\title{
POTENSI TUMBUHAN LIBO (Ficus variegata, Blume) SEBAGAI SUMBER BAHAN FARMASI POTENSIAL
}

\author{
Laode Rijai \\ Laboratorium Penelitian dan Pengembangan Kefarmasian FARMAKA TROPIS \\ Fakultas Farmasi Universitas Mulawarman
}

\begin{abstract}
ABSTRAK
Libo (Ficus varieagata) merupakan tumbuhan liar yang belum termanfaatkan dalam bentuk apapun, termasuk secara tradisional karena tumbuhan ini memiliki latex pada buah dan kulit batangnya dan jika latex tersebut mengenai kulit menimbulkan gatal-gatal bahkan terjadi iritasi. Sifat ini yang menyebabkan tidak disukai hewan pemakan buah sehingga buahnya terpelihara dengan baik. Buah Libo yang telah matang di pohon akan jatuh ke tanah lalu tumbuh menjadi pohon Libo dewasa.Potensi tumbuhan Libo berbuah terus menerus dan buahnya tidak disukai hewan pemakan buah sehingga populasi tumbuhan Libo terpelihara dan terus berkembang. Telah dilakukan berbagai penelitian terhadap buah Libo kaitannya dengan potensi kefarmasian dan terbukti berpotensi sebagai sumber bahan antioksidan, sitotoksik atau antikanker, pembasmi larva A. aegypti, dan sebagai antibakteri. Potensi-potensi tersebut dapat dimanfaatkan sebagai pengawet, obat antikanker, dan sumber antibiotik jika penelitiannya dilakukan secara detail. Buah Libo juga mengandung golongan metabolit sekunder yang sangat bervariasi sehingga masih memungkinkan untuk kegunaan-kegunaan lainnya dalam bidang farmasi.
\end{abstract}

Kata Kunci: Tumbuhan Libo (Ficus variegata), bahan farmasi potensial

\begin{abstract}
Libo ( Ficus varieagata) is a wild plant that has not been utilized in any form, including traditional because it has latex plant fruit and bark, and if the latex on the skin cause itching occurs even irritation. The nature of that cause undesirable fruit so that the fruit -eating animals are well maintained. Libo ripe fruit on the tree will fall to the ground and grow into a tree Libo Libo dewasa.Potensi plant fruiting and fruit continuously disliked fruit -eating animals that populations of plants Libo maintained and continues to grow. Has conducted numerous studies on fruit Libo relation with potential pharmaceutical and proven potential as a source of antioxidant, cytotoxic or anticancer, exterminator larval A. aegypti, and as an antibacterial. These potentials can be used as a preservative, an anticancer drug, and a source of antibiotics if the research is done in detail. Libo fruit also contains a group of secondary metabolites are highly variable so it still allows for other uses - uses in the pharmaceutical field .
\end{abstract}

Key Words: Tumbuhan Libo (Ficus variegata), bahan farmasi potensial 


\section{PENDAHULUAN}

Manfaat tradisional buah tumbuhan Libo ( $F$. variegata) tidak banyak dikenal, kecuali beberapa spesies yang termasuk genus Ficus di antaranya sebagai obat diare, sedangkan daunnya digunakan untuk membersihkan selaput mata. Potensi tumbuhan Libo ( $F$. variegata) yang tampak adalah berbuah secara terus menerus, jumlah buahnya sangat banyak yang menempel pada seluruh permukaan batang dan ranting pohon. Buah Libo yang telah matang di pohon akan jatuh ke tanah dan selanjutnya buah tersebut akan tumbuh hingga menjadi pohon Libo dewasa. Hewan pemakan buah Libo juga sangat langka sehingga kelangsungan hidup tumbuhan Libo sangat baik. Pemanfaatan pohon Libo untuk perkayuan juga tidak potensial karena struktur kayu batangnya tidak memenuhi syarat untuk bahan bangunan yaitu didominasi serat selulosa dibandingkan lignan. Karena itu kegunaan tumbuhan Libo masih sangat minim dengan karakteristiknya yang demikian, meskipun potensi kelestariannya cukup baik. Cara untuk memanfaatkan tumbuhan Libo dengan potensi tersebut haruslah dilakukan berbagai penelitian yang diarahkan pada potensi bidang farmasi terutama obat. Namun demikian penelitian tentang tumbuhan Libo ( $F$. variegata) juga masih sangat minim sehingga informasi kemanfaatannya juga sangat minim. Hewan pemakan buah-buahan hutan enggan memakan buah Libo sehingga terbuang begitu saja.

Pemanfaatan tumbuhan Libo khususnya buah dapat saja dilakukan dalam bidang farmasi karena ciri khas potensi farmasi dari bahan alam adalah terkait dengan obat, makanan-minuman fungsional, serta sebagai kosmetik sehat. Buah Libo yang tidak disukai hewan pemakan buah mengindikasikan terdapat sejumlah senyawa dalam buah Libo yang bersifat toksik atau rasa yang tidak nyaman. Sifatsifat tersebut merupakan hal penting dalam bidang farmasi misalnya sifat toksik berpotensi sebagai obat kanker dengan prinsip dasar pembunuh sel (kemoterapi), sifat toksik sebagai antimikroba, pestisida (insektisida, larvasida, bakterisida, fungisida, fisisida), dan lain-lain. Tumbuhan Libo yang mudah dibudidayakan, berbuah secara terus menerus merupakan potensi yang luar biasa dan harus dimanfaatkan. Gambar 1 adalah contoh tumbuhan Libo ( $F$. variegata).
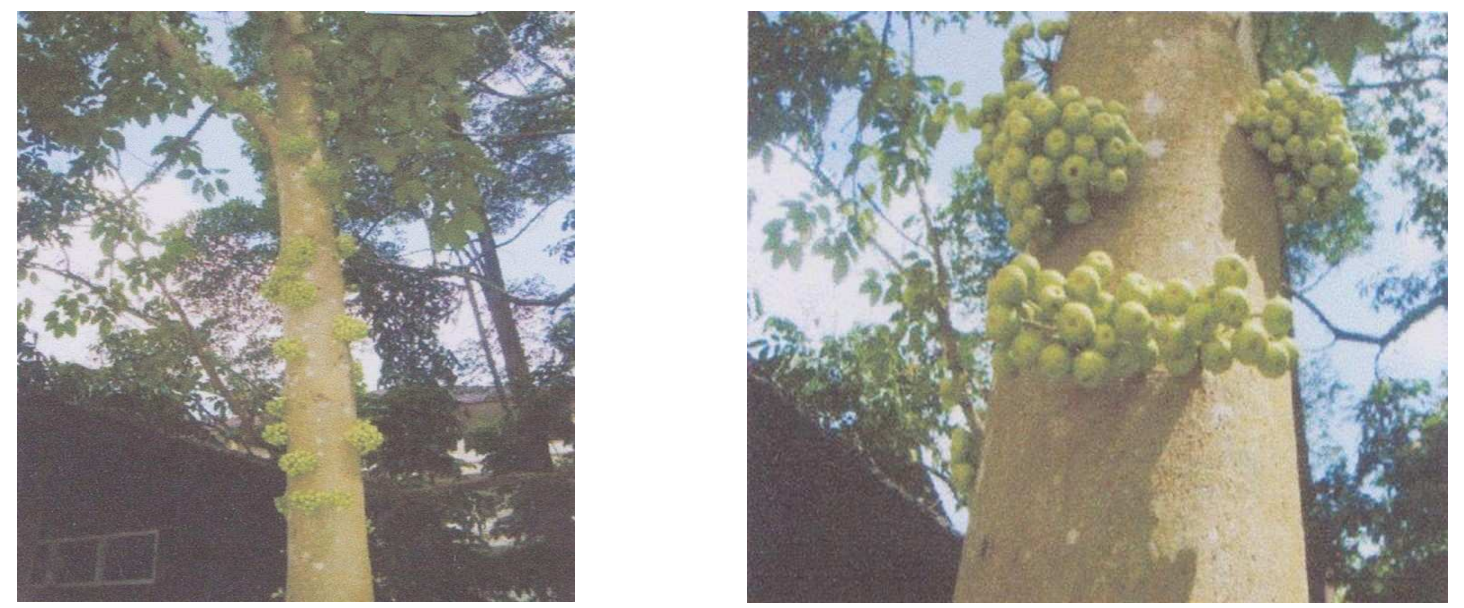

Gambar 1.1. Contoh tumbuhan Libo ( $F$. variegata) 


\section{METODOLOGI PENELITIAN}

Potensi tumbuhan Libo ( $F$. variegata) yang dilaporkan pada artikel ini adalah (a) aktivitas antioksidan ekstrak buah Libo (b) aktivitas antibakteri (c) larvasida (d) sitotoksik atau antikanker dan (e) kandungan metabolit sekundernya.

\section{a. Pengambilan Bahan Tumbuhan}

Buah Libo diambil dari halaman gedung Dekanat Fakultas Farmasi Universitas Mulawarman yang setiap saat memiliki buah terutama pada musim kemarau memiliki buah yang lebih banyak daripada pada musim hujan. Buah Libo yang diambil selanjutnya dirajang setelah dicuci, kemudian dikeringkan pada sinar matahari langsung. Buah Libo yang telah kering diblender dan diperoleh serbuk kering sebanyak 5,45 kg. Buah Libo disortir sedemikian rupa untuk mendapatkan buah yang bersih atau tanpa kontaminan partikel lain pada permukaan buah.

\section{b. Ekstraksi Pekat Etanol dan Fraksinasi}

Serbuk kering sebanyak 5,45 kg yang telah disiapkan diekstraksi dengan teknik maserasi dingin dengan pelarut etanol 80 $\%$. Pergantian pelarut selama ekstraksi dilakukan sebanyak 6 kali untuk mendapatkan larutan ekstrak yang maksimal. Kegiatan ekstraksi dihentikan setelah seluruh metabolit sekunder yang ada dalam serbuk buah Libo telah terekstraksi ke dalam pelarut etanol. Indikator telah terekstraksi semua metabolit sekunder Libo adalah larutan ekstrak menjadi bening dibandingkan dengan sebelumnya dan juga dilakukan analisis kromtografi lapis tipis (KLT). Larutan ekstrak yang diperoleh segera diuapkan pelarutnya dengan menggunakan
Rotavapor pada suhu $30{ }^{\circ} \mathrm{C}$ dan diperoleh ekstrak sebanyak $246,6 \mathrm{~g}$.

Ekstrak pekat etanol buah Libo yang telah diperoleh, selanjutnya dilakukan fraksinasi dengan teknik cair-cair menggunakan pelarut aquades. Fraksinasi dilakukan secara gradien yang dimulai dari pelarut $n$ heksana, etilasetat, $n$-butanol, dan sisanya fraksi air. Ekstrak pekat etanol yang digunakan untuk fraksinasi adalah $150 \mathrm{~g}$ dan diperoleh fraksi seperti yang ditunjukkan pada Tabel 1.

Tabel 1. Ekstrak pekat etanol dan fraksifraksi buah Libo ( $F$. varieagata)

\begin{tabular}{clc}
\hline No & \multicolumn{1}{c}{ Ekstrak } & Bobot $(\mathbf{g})$ \\
\hline 1 & Ekstrak pekat etanol & 246,6 \\
2 & Ekstrak fraksi $n$-heksana & 38,80 \\
3 & Ekstrak fraksi etilasetat & 32,45 \\
4 & Ekstrak fraksi $n$-butanol & 34,78 \\
5 & Ekstrak fraksi air & 21,84 \\
\hline
\end{tabular}

\section{c. Uji Aktivitas Sitotoksik}

Uji sitotoksik dilakukan secara in vitro dengan menggunakan teknik BSLT dengan bioindikator larva udang Artemia salina. Hasil pengujian akan menggambarkan potensi sitotoksik jika nilai LC50 $\leq 30$ ppm (Rapael, 1991).

\section{Penyiapan Bioindikator Uji}

Sekitar $200 \mathrm{mg}$ telur A. salina ditetaskan dalam wadah erlenmeyer yang telah disiapkan pada temperatur yang sesuai dengan temperatur tetas yaitu dengan pemberian pemanasan dengan cahaya lampu pijar 60 watt. Penetasan berlangsung 72 jam, dan mulai 48 jam telah diperoleh larva yang siap untuk diuji.

\section{Penentuan Konsentrasi Sampel Uji}

Prinsip dasar penentuan konsentrasi uji untuk pengujian toksisitas ataupun 
sitotoksik adalah membentuk garis linier hubungan antara variasi konsentrasi uji dengan jumlah larva bioindikator yang mati, sehingga nilai LC50 dapat ditentukan. Setiap ekstrak ditentukan variasi konsentrasi dengan cara membuat konsentrasi rendah dan konsentrasi tinggi untuk memperkirakan seri konsentrasi yang akan dibuat. Tabel 2 adalah konsentrasi uji yang telah ditemukan dalam penentuan seri konsentrasi.

Tabel 2. Variasi konsentrasi sampel uji untuk pengujian aktivitas sitotoksik ekstrak buah Libo (F. varieagata)

\begin{tabular}{clccccc}
\hline \multirow{2}{*}{ No } & \multicolumn{1}{c}{ Ekstrak } & \multicolumn{5}{c}{ Variasi Konsentrasi Ekstrak buah Libo dalam ppm } \\
\cline { 3 - 6 } & & I & II & III & IV & V \\
\hline 1 & Ekstrak pekat etanol & 5 & 10 & 15 & 20 & 25 \\
2 & Ekstrak fraksi $n$-heksana & 10 & 15 & 20 & 25 & 30 \\
3 & Ekstrak fraksi etilasetat & 5 & 10 & 15 & 20 & 25 \\
4 & Ekstrak fraksi $n$-butanol & 5 & 10 & 15 & 20 & 25 \\
5 & Ekstrak fraksi air & 10 & 15 & 20 & 25 & 30 \\
\hline
\end{tabular}

\section{Pengujian Aktivitas Sitotoksik Ekstrak Buah Tumbuhan Libo}

Uji kemampuan ekstrak mematikan larva A. salina menggambarkan toksisitas dan pada nilai LC50 < 30 ppm mengindikasikan potensi sitotoksik atau antikanker. Seluruh ekstrak buah Libo yang telah diperoleh dilakukan uji kemampuannya dalam mematikan larva udang A. salina pada konsentrasi setiap ekstrak yang telah ditemukan. Pengujian dilakukan dalam wadah erlenmeyer ukuran $50 \mathrm{~mL}$ dengan jumlah larva $A$. salina setiap wadah perlakuan berjumlah 10 larva. Pengamatan dilakukan setiap 3 jam sampai dengan 12 jam, seperti yang telah dilakukan pada penentuan konsentrasi ekstrak uji.

\section{d. Uji Antioksidan}

Aktivitas antioksidan merupakan sifat kimia suatu senyawa yang dapat dimanfaatkan dalam bidang farmasi, yaitu sebagai obat atau pengawet sediaan farmasi. Seluruh ekstrak buah Libo telah dilakukan uji antioksidan terhadap senyawa radikal bebas DPPH.

\section{Penyiapan Larutan DPPH}

Senyawa radikal DPPH merupakan indikator uji yang memiliki reaktivitas tinggi karena memiliki satu elektron tak berpasangan pada atom nitrogen yang dikandungya. Larutan DPPH yang digunakan pada pengujian ini 40 ppm yang lazim digunakan dalam setiap penelitian terhadap ekstrak yang tidak diketahui kandungan senyawanya. Pelarut DPPH yang digunakan adalah metanol.

\section{Penentuan Seri Konsentrasi Sampel Uji}

Prinsip dasar penentuan seri konsentrasi sampel uji pada setiap pegujian antioksidan harus diperoleh hubungan linier antara konsentrasi sampel uji dengan penurunan nilai absorbansi larutan DPPH. Nilai konsentrasi uji setiap ekstrak ditetapkan secara acak yang akan diuji hingga ditemukan nilai konsentrasi yang membentuk garis linier hubungan antara seri konsentrasi dengan nilai absorbansi perlakuan. Tabel 3 adalah variasi konsentrasi sampel uji pada pengujian antioksidan. 
Tabel 3. Variasi konsentrasi sampel untuk pengujian aktivitas antioksidan ekstrak buah Libo $(F$, varieagata $)$

\begin{tabular}{clccccc}
\hline \multirow{2}{*}{ No } & \multirow{2}{*}{ Ekstrak } & \multicolumn{5}{c}{ Variasi Konsentrasi Ekstrak buah Libo dalam ppm } \\
\cline { 3 - 7 } & & I & II & III & IV & V \\
\hline 1 & Ekstrak pekat etanol & 25 & 35 & 45 & 55 & 65 \\
2 & Ekstrak fraksi n-heksana & 30 & 40 & 50 & 60 & 70 \\
3 & Ekstrak fraksi etilasetat & 10 & 20 & 30 & 40 & 50 \\
4 & Ekstrak fraksi n-butanol & 20 & 30 & 40 & 50 & 60 \\
5 & Ekstrak fraksi air & 40 & 60 & 80 & 100 & 120 \\
\hline
\end{tabular}

\section{Pengujian Antioksidan}

Pelaksanaan pengujian antioksidan yang sesungguhnya sama dengan penentuan seri konsentrasi uji dengan menggunakan nilai konsentrasi uji yang telah ditemukan. Pelarut ekstrak juga menggunakan metanol sehingga khusus ekstrak fraksi non polar ditambahkan dengan DMSO untuk melarutkannya dengan ukuran maksimal 1 $\%$ sebanyak $2 \mathrm{~mL}$. Pengujian telah dilakukan dengan baik.

\section{e. Uji Antibakteri}

Bakteri uji yang digunakan adalah Staphylococcus aureus, Bacillus subtilis, Escherchia coli, dan Pseudomonas aeruginosa. Keempat bakteri tersebut memiliki peran penting terhadap terjadinya penyakit pada masyarakat.

\section{Pembuatan Medium Tumbuh Bakteri}

Medium yang digunakan adalah Nutrien Agar (NA) dengan komposisi ekstrak beef $3 \mathrm{~g}$, pepton $5 \mathrm{~g}$, Agar $15 \mathrm{~g}$, dan pelarut aquades $1000 \mathrm{~mL}$. Seluruh bahan dicampur dengan pelarut air lalu dipanaskan dengan hot plate dan disterilkan dalam autoklaf pada temperatur $121{ }^{\circ} \mathrm{C}$ selama 15 menit.

\section{Penyiapan Bakteri Uji}

Biakan murni bakteri uji diinokulasi dalam media lalu disuspensikan dengan larutan $\mathrm{NaCl}$ 0,9 \% steril dan diperoleh suspensi bakteri. Suspensi bakteri siap untuk diuji.

\section{Penentuan Konsentrasi Sampel Uji}

Prinsip dasar penentuan seri konsentrasi uji antibakteri adalah menentukan daya bunuh maksimum setiap ekstrak. Nilai konsentrasi ditetapkan secara acak lalu kemudian dilakukan pengujian hingga mendapatkan hubungan antara zona hambat/bunuh dengan variasi konsentrasi sampel membentuk kurva hiperball atau parabola terbalik. Nilai konsentrasi uji yang diambil secara acak ada tiga yaitu konsetrasi terendah yang telah dpat memberikan daya hambat/bunuh terhadap bakteri, dan juga menetapkan nilai konsentrasi uji yang memberikan daya hambat tertinggi dan nilai konsentrasi yang menunjukkan daya bunuh/hambat mulai menurun. Tabel $4-7$ adalah variasi konsentrasi uji yang telah ditemukan pada penentuan seri konsentrasi uji antibakteri. 
Tabel 4. Variasi konsentrasi uji antibakteri ekstrak buah Libo (F. variegata) terhadap bakteri Bacillus subtillis

\begin{tabular}{clccccc}
\hline \multirow{2}{*}{ No } & \multicolumn{2}{c}{ Ekstrak } & \multicolumn{5}{c}{ Variasi Konsentrasi Ekstrak buah Libo dalam \% } \\
\cline { 3 - 7 } & & I & II & III & IV & V \\
\hline 1 & Ekstrak pekat etanol & 0,5 & 1,0 & 1,5 & 2,0 & 2,5 \\
2 & Ekstrak fraksi n-heksana & 1,0 & 2,0 & 3,0 & 4,0 & 5,0 \\
3 & Ekstrak fraksi etilasetat & 1,0 & 2,0 & 3,0 & 4,0 & 5,0 \\
4 & Ekstrak fraksi n-butanol & 2,0 & 4,0 & 6,0 & 8,0 & 10,0 \\
5 & Ekstrak fraksi air & 2,0 & 4,0 & 6,0 & 8,0 & 10,0 \\
\hline
\end{tabular}

Tabel 5. Variasi konsentrasi uji antibakteri ekstrak buah Libo (F. variegata) terhadap bakteri Escherchia coli

\begin{tabular}{clccccc}
\hline \multirow{2}{*}{ No } & \multicolumn{1}{c}{ Ekstrak } & \multicolumn{5}{c}{ Variasi Konsentrasi Ekstrak buah Libo dalam \% } \\
\cline { 3 - 7 } & & I & II & III & IV & V \\
\hline 1 & Ekstrak pekat etanol & 1,0 & 1,5 & 2,0 & 2,5 & 3,0 \\
2 & Ekstrak fraksi n-heksana & 5 & 10 & 15 & 20 & 25 \\
3 & Ekstrak fraksi etilasetat & 2 & 4 & 6 & 8 & 10 \\
4 & Ekstrak fraksi n-butanol & 1 & 3 & 5 & 7 & 9 \\
5 & Ekstrak fraksi air & 10 & 15 & 20 & 25 & 30 \\
\hline
\end{tabular}

Tabel 6. Variasi konsentrasi uji antibakteri ekstrak buah Libo (F. variegata) terhadap bakteri Staphylococcus aureus

\begin{tabular}{clccccc}
\hline \multirow{2}{*}{ No } & \multicolumn{2}{c}{ Ekstrak } & \multicolumn{5}{c}{ Variasi Konsentrasi } & Ekstrak buah Libo dalam \% \\
\cline { 3 - 7 } & & I & II & III & IV & V \\
\hline 1 & Ekstrak pekat etanol & 1,5 & 2,5 & 3,5 & 4,5 & 5,5 \\
2 & Ekstrak fraksi n-heksana & 5 & 10 & 15 & 20 & 25 \\
3 & Ekstrak fraksi etilasetat & 3 & 5 & 7 & 9 & 11 \\
4 & Ekstrak fraksi $n$-butanol & 1 & 2 & 3 & 4 & 5 \\
5 & Ekstrak fraksi air & 5 & 10 & 15 & 20 & 25 \\
\hline
\end{tabular}

Tabel 7. Variasi konsentrasi uji antibakteri ekstrak buah Libo (F. variegata) terhadap bakteri Pseudomonas aeruginosa

\begin{tabular}{clccccc}
\hline \multirow{2}{*}{ No } & \multicolumn{2}{c}{ Ekstrak } & \multicolumn{5}{c}{ Variasi Konsentrasi } & Ekstrak buah Libo dalam \% \\
\cline { 3 - 7 } & & I & II & III & IV & V \\
\hline 1 & Ekstrak pekat etanol & 1 & 3 & 5 & 7 & 9 \\
2 & Ekstrak fraksi n-heksana & 5 & 10 & 15 & 20 & 25 \\
3 & Ekstrak fraksi etilasetat & 3 & 6 & 9 & 12 & 15 \\
4 & Ekstrak fraksi $n$-butanol & 1 & 2 & 3 & 4 & 5 \\
5 & Ekstrak fraksi air & 10 & 15 & 20 & 25 & 30 \\
\hline
\end{tabular}




\section{f. Uji Aktivitas Ekstrak Terhadap Larva Aedes aegypti}

Karakteristik buah Libo yang tidak disukai hewan pemakan buah menjadi dasar pengujian terhadap berbagai toksisitas termasuk sebagai pembasmi larva $A$. aegypti.

\section{Penyiapan Larva Aedes aegypti}

Telur nyamukA. aegyptidiperoleh dari Fakultas Kedokteran Hewan Institut Pertanian Bogor. Umur telur nyamuk tersebut maksimal 3 bulan dan harus ditempatkan pada tempat yang tidak lembab. Penetesan telur $A$. aegypti untuk menjadi larva sangat mudah yaitu dengan menambahkan air aquades dengan makanan ekstrak hati ayam, selama 48 hingga 72 jam akan menetas dan menghasilkan larva yang siap untuk diuji. Pengujian sama persis dengan metode BSLT. Pada penelitian ini sebanyak 100 mg telur ditetaskan pada wadah yang telah dijelaskan sebelumnya.

\section{Penentuan Seri Konsentrasi Sampel Uji}

Prinsip dasar penentuan seri konsentrasi uji sama dengan pengujian pada metode BSLT yaitu harus diperoleh kurva garis lurus hubungan antara nilai konsentrasi uji dengan jmulah larva yang mati. Tabel 8 menunjukkan variasi konsentrasi uji yang telah ditemukan.

\section{Pengujian Larvasida}

Konsentrasi ekstrak sampel yang telah ditemukan dilakukan pengujian terhadap kematian larva A. aegypty. Wadah pengujian menggunakan labu erlenmeyer ukuran $50 \mathrm{~mL}$ dengan jumlah larva setiap perlakuan adalah 10 larva. Pengamatan yang dilakukan adalah penghitungan jumlah larva yang mati pada setiap perlakuan seri konsentrasi sampel uji.

Tabel 8. Variasi konsentrasi uji larvasida ekstrak buah Libo (F. variegata) terhadap larva nyamuk Aedes aegypty

\begin{tabular}{clccccc}
\hline \multirow{2}{*}{ No } & \multicolumn{1}{c}{ Ekstrak } & \multicolumn{5}{c}{ Variasi Konsentrasi Ekstrak buah Libo dalam ppm } \\
\cline { 3 - 7 } & & I & II & III & IV & V \\
\hline 1 & Ekstrak pekat etanol & 10 & 20 & 30 & 40 & 50 \\
2 & Ekstrak fraksi $n$-heksana & 15 & 30 & 45 & 60 & 75 \\
3 & Ekstrak fraksi etilasetat & 10 & 20 & 30 & 40 & 50 \\
4 & Ekstrak fraksi $n$-butanol & 5 & 10 & 15 & 20 & 25 \\
5 & Ekstrak fraksi air & 10 & 20 & 30 & 40 & 50 \\
\hline
\end{tabular}

\section{g. Uji Golongan Metabolit Sekunder}

Uji golongan metabolit sekunder dilakukan terhadap ekstrak pekat etanol dan tidak dilakukan terhadap ekstrak fraksifraksinya. Hasil uji terhadap ekstrak pekat akan menggambarkan kandungan metabolit sekunder pada fraksi-fraksinya. Seluruh golongan metabolit sekunder dilakukan skrining dengan menggunakan pereaksi khas terhadap masing-masing golongan metabolit sekunder. Wadah uji skrining metabolit sekunder adalah plat tetes dengan indikator uji pada umumnya adalah penampakan warna. 


\section{HASIL DAN PEMBAHASAN}

Potensi buah tumbuhan Libo ( $F$. varieagata) yang dilaporkan adalah (a) aktivitas sitotoksik secara invitro (b) antioksidan (c) antibakteri (d) larvasida terhadap A. aegypty dan (e) profil golongan metabolit sekunder. Seluruh variabel tersebut merupakan potensi yang terkait dengan kefarmasian sehingga buah tumbuhan Libo merupakan sumber bahan farmasi yang potensial.

\section{A. Potensi Buah Libo Sebagai Sumber Obat Sitotoksik}

Potensi sitotoksik suatu bahan dapat digambarkan dengan hasil uji secara in vitro terhadap kemtian larva udang $A$. salina. Potensi sitotoksik buah tumbuhan Libo yang dilaporkan pada artikel ilmiah ini merupakan hasil pengujian secara in vitro dengan menggunakan bioindikator $A$. salina. Seluruh ekstrak buah Libo yang telah diperoleh telah dilakukan uji aktivitas terhadap kematian larva udang $A$.
salina.Hasil pengujian potensi sitotoksik ekstrak buah Libo ditunjukkan pada Tabel 9.

Hasil uji aktivitas ekstrak terhadap kematian larva A. salina menggambarkan bahwa seluruh ekstrak buah Libo bersifat sitotoksik karena nilai LC50 lebih kecil dari $30 \mathrm{ppm}$. Potensi ini tidak dapat secara serta merta dapat dimanfaatkan sebagai obat kanker meskipun larva A. salina telah digunakan sebagai uji potensi antikanker dan hasilnya memenuhi syarat sebagai antikanker. Kegiatan penting yang dapat dilakukan sebelum pemanfaatannya adalah uji toksisitas ekstrak buah Libo terhadap hewan uji karena buah Libo di alam dikenal beracun sehingga hewan pemakan buah tidak tertarik terhadap buah tersebut. Kegiatan penting lainya terkait dengan pemanfaatan buah Libo adalah uji antikanker secara spesifik yaitu terhadap sel kanker seperti sel hela. Jika hasil uji toksisitas dan uji spesifik telah dilakukan dengan baik maka buah Libo telah dapat dimanfaatkan sebagai obat kanker.

Tabel 9. Aktivitas ekstrak buah Libo (F. varieagata) terhadap larva A. salina

\begin{tabular}{clc}
\hline No & \multicolumn{1}{c}{ Ekstrak Sampel } & Nilai LC50 dalam ppm \\
\hline 1 & Ekstrak pekat etanol & 15,82 \\
2 & Ekstrak fraksi $n$-heksana & 23,54 \\
3 & Ekstrak fraksi etilasetat & 11,53 \\
4 & Ekstrak fraksi $n$-butanol & 10,26 \\
5 & Ekstrak fraksi air & 28,62 \\
\hline
\end{tabular}

Sumber: Wijaya (2012)

\section{B. Potensi Eksrak Buah Libo Sebagai Sumber Antioksidan}

Antioksidan adalah suatu sifat kimia molekul yang dapat dimanfaatkan dalam bidang farmasi khususnya sebagai bahan obat, makanan fungsional, kosmetik, dan pengawet sediaan farmasi. Fungsi sifat antioksidan sebagai obat dan makananminuman fungsional terkait dengan kemampuan meredam radikal bebas berbahaya sehingga tidak terjadi reaksi antara senyawa radikal dengan metabolit dalam sel. Selain itu, antioksidan juga dapat membantu kinerja metabolisme sehingga dapat berefek pada penyembuhan 
penyakit degeneratif tertentu. Selanjutnya, dalam bidang kosmetik terkait dengan efeknya yaitu mengembalian kebugaran kulit sehingga tampak awet muda dari yang sesungguhnya. Kaitannya dengan pengawet adalah mencegah terjadinya oksidasi sehingga reaksi internal suatu sediaan farmasi dapat dicegah atau diperlambat.

Hasil uji antioksidan ekstrak buah Libo terhadap senyawa radikal bebas DPPH ditunjukkan pada Tabel 10.

Buah Libo menunjukkan potensi antioksidan yang sangat kuat yaitu seluruh ekstrak menunjukkan nilai IC50 di bawah 100 ppm, sedangkan tingkat kekuatan bahan yang masih termasuk kategori antioksidan memiliki nilai IC50 < $200 \mathrm{ppm}$ (Rapael, 1991). Potensi antioksidan buah Libo yang dilaporkan pada Tabel 10 tersebut tidak dapat dimanfaatkan secara serta merta karena buah Libo dikenal dapat menyebabkan iritasi pada kulit sehingga masih diperlukan penelitian deteksi antioksidan dikaitkan dengan pengolahan. Namun demikian data tersebut buah Libo telah memenuhi syarat untuk dianggap sebagai sumber antioksidan potensial.

Tabel 10. Aktivitas antioksidan ekstrak buah Libo ( $F$. varieagata) terhadap senyawa radikal bebas DPPH

\begin{tabular}{clc}
\hline No & \multicolumn{1}{c}{ Ekstrak Sampel } & Nilai IC50 dalam ppm \\
\hline 1 & Ekstrak pekat etanol & 47,85 \\
2 & Ekstrak fraksi n-heksana & 55,65 \\
3 & Ekstrak fraksi etilasetat & 28,44 \\
4 & Ekstrak fraksi n-butanol & 25,46 \\
5 & Ekstrak fraksi air & 82,46 \\
\hline
\end{tabular}

Sumber: Titin (2013)

\section{Potensi Buah Libo Sebagai Antibakteri}

Aktivitas suatu molekul sebagai antibakteri merupakan potensi penting dalam bidang farmasi. Buah Libo telah dilakukan uji antibakteri terhadap 4 jenis bakteri yaitu $S$. aureus, E. coli, $P$. aerugunosa, dan $B$. subtillis. Hasil uji antibakteri terhada keempat jenis bakteri tersebut ditunjukkan pada Tabel $11-14$.

Empat bakteri uji yang digunakan untuk mendeteksi kemampuan antibakteri ekstrak buah Libo semuanya memberikn efek antibakteri yang sangat baik, ditinjau dari konsentrasi uji yang digunakan setiap ekstrak dan juga daya bunuh yang dihasilkan. Ekstrak paling kuat sebagai antibakteri adalah ekstrak fraksi $n$-butanol terhadap keempat jenis bakteri uji yaitu berkisar pada zona > $8 \mathrm{~mm}$ dengan konsentrasi terbaik membunuh bakter ratarata kurang dari $6 \%$. Fenomena ini menunjukkan bahwa ekstrak buah Libo sangat baik sebagai sumber antibakteri yang sangat potensial.

\section{Potensi Ekstrak Libo Sebagai Pembasmi Aedes aegypty}

Sifat buah Libo yang tidak disukai serangga dimaknai memiliki kandungan kimia yang bersifat repelen atau toksik terhadap serangga. Berdasarkan dugaan tersebut maka dilakukan uji larvasida terhadap larva nyamuk $A$. aegypti. Hasil uji larvasida terhadap larva nyamuk $A$. aegypti ditunjukkan pada Tabel 15 . 
Tabel 11. Hasil uji antibakteri ekstrak buah Libo (F. varieagata) terhadap bakteri Bacillus subtillis

\begin{tabular}{|c|c|c|c|}
\hline Ekstrak Sampel & $\begin{array}{c}\text { Kons. Ekstrak } \\
\text { dalam }(\%)\end{array}$ & $\begin{array}{l}\text { Zona Bunuh } \\
(\mathrm{mm})\end{array}$ & $\begin{array}{l}\text { Konsentrasi } \\
\text { terbaik }(\%)\end{array}$ \\
\hline \multirow{5}{*}{ Ekstrak pekat etanol } & 0,5 & 4,54 & \multirow[t]{5}{*}{ 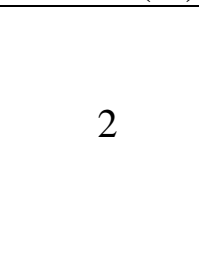 } \\
\hline & 1,0 & 5,82 & \\
\hline & 1,5 & 8,63 & \\
\hline & 2,0 & 9,82 & \\
\hline & 2,5 & 8,46 & \\
\hline \multirow{5}{*}{ Ekstrak fraksi $n$-heksana } & 1,0 & 3,64 & \multirow{5}{*}{3,0} \\
\hline & 2,0 & 3,84 & \\
\hline & 3,0 & 4,68 & \\
\hline & 4,0 & 3,74 & \\
\hline & 5,0 & 3,66 & \\
\hline \multirow{5}{*}{ Ekstrak fraksi etilasetat } & 1,0 & 6,86 & \multirow{5}{*}{4,0} \\
\hline & 2,0 & 7,47 & \\
\hline & 3,0 & 8,65 & \\
\hline & 4,0 & 8,68 & \\
\hline & 5,0 & 8,12 & \\
\hline \multirow{5}{*}{ Ekstrak fraksi n-butanol } & 2,0 & 8,29 & \multirow{5}{*}{8,0} \\
\hline & 4,0 & 9,64 & \\
\hline & 6,0 & 13,66 & \\
\hline & 8,0 & 14,25 & \\
\hline & 10,0 & 12,88 & \\
\hline \multirow{5}{*}{ Ekstrak fraksi air } & 2,0 & 4,67 & \multirow{5}{*}{6,00} \\
\hline & 4,0 & 4,98 & \\
\hline & 6,0 & 7,88 & \\
\hline & 8,0 & 7,67 & \\
\hline & 10,0 & 7,46 & \\
\hline
\end{tabular}

Sumber: Ramadhani (2012) 
Tabel 12. Hasil uji antibakteri ekstrak buah Libo (F. varieagata) terhadap bakteri E. coli

\begin{tabular}{cccc}
\hline No $\quad$ Ekstrak Sampel & $\begin{array}{c}\text { Kons. Ekstrak } \\
\text { dalam }(\%)\end{array}$ & $\begin{array}{c}\text { Zona Bunuh } \\
(\mathrm{mm})\end{array}$ & $\begin{array}{c}\text { Konsentrasi } \\
\text { terbaik }(\%)\end{array}$ \\
\hline \multirow{3}{*}{ Ekstrak pekat etanol } & 1,0 & 4,65 & \\
& 1,5 & 5,62 & 2,5 \\
& 2,0 & 7,88 & \\
Ekstrak fraksi $n$-heksana & 2,5 & 8,80 & \\
& 3,0 & 7,23 & \\
& 5 & 3,84 & \\
& 10 & 4,12 & \\
& 15 & 4,84 & \\
& 20 & 5,24 & \\
Ekstrak fraksi etilasetat & 25 & 4,98 & \\
& 2 & 6,2 & \\
& 4 & 6,6 & \\
& 6 & 6,8 & \\
& 8 & 7,6 & \\
Ekstrak fraksi n-butanol & 10 & 7,21 & \\
& 1 & 6,66 & \\
& 3 & 8,42 & \\
& 5 & 10,23 & \\
& 7 & 14,22 & \\
& 9 & 13,12 & \\
& 10 & 7,68 & \\
& 15 & 7,69 & \\
& 20 & 7,86 & \\
& 25 & 10,02 & \\
& 30 & 9,87 & \\
& & &
\end{tabular}

Sumber: Ramadhani (2012) 
Tabel 13. Hasil uji antibakteri ekstrak buah Libo ( $F$. varieagata) terhadap bakteri Staphylococcus aureus

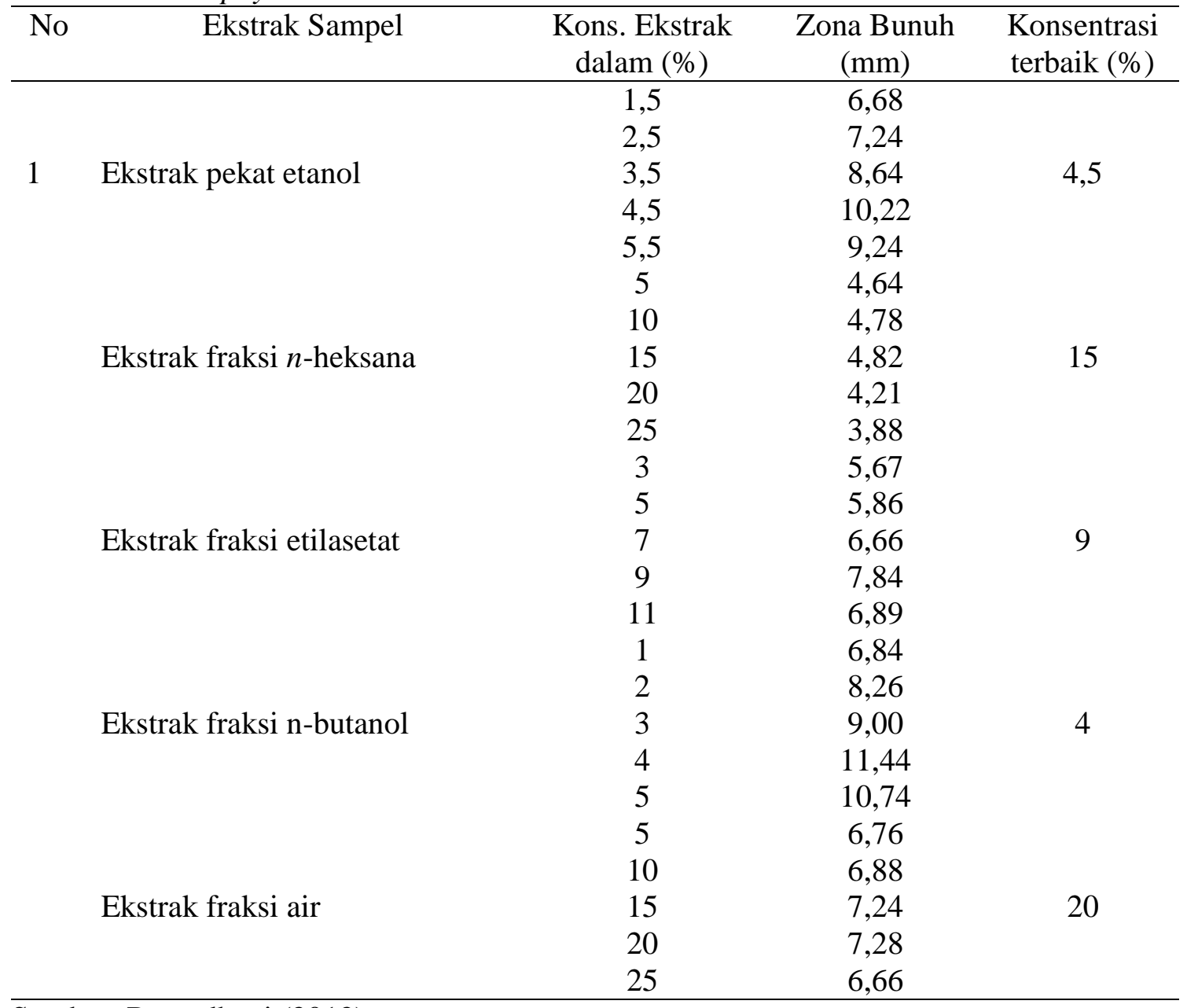

Sumber: Ramadhani (2012) 
Tabel 14. Hasil uji antibakteri ekstrak buah Libo ( $F$. varieagata) terhadap bakteri Pseudomonas aeruginosa

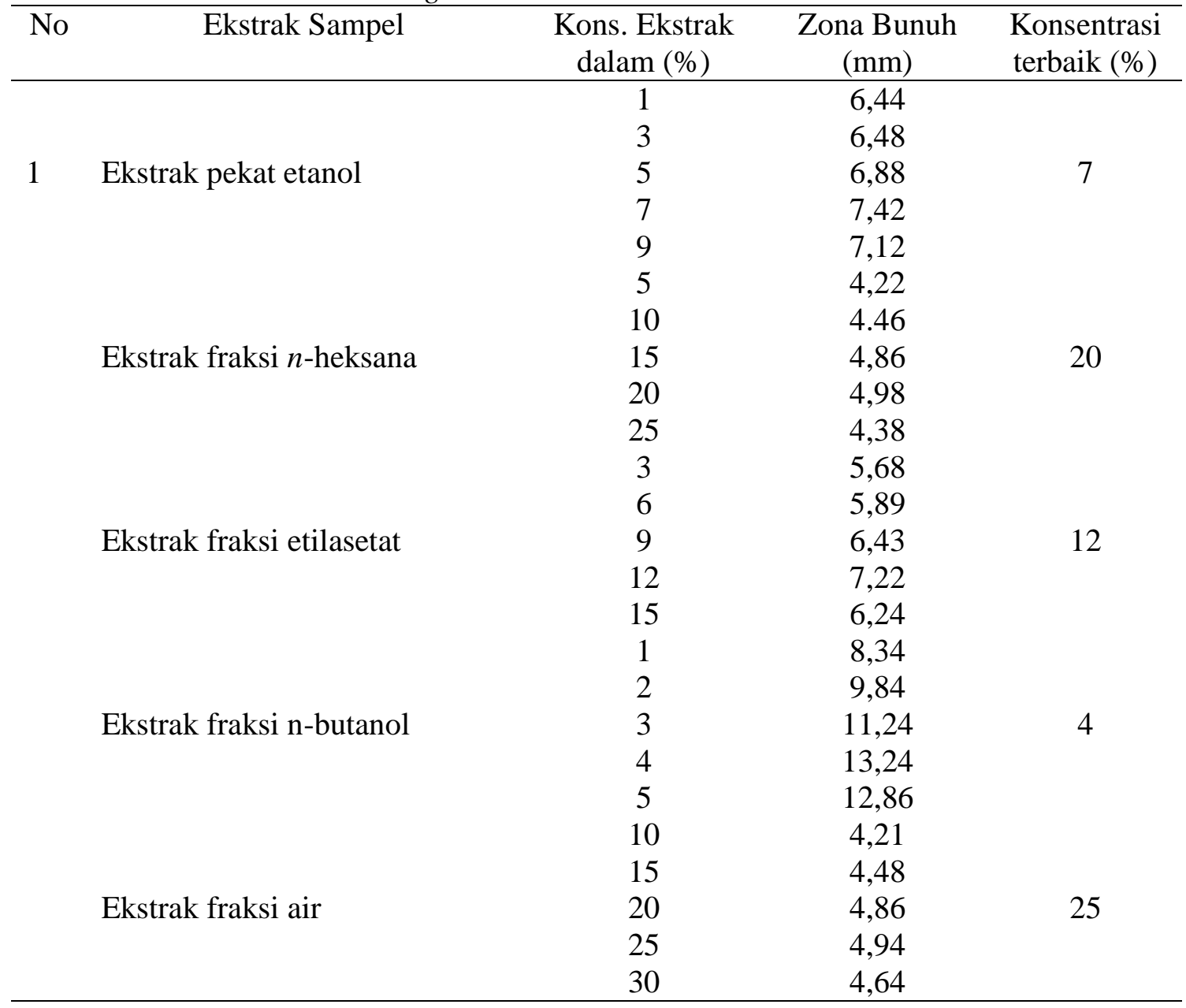

Sumber: Ramadhani (2012).

Tabel 15. Aktivitas larvasida ekstrak buah Libo (F. varieagata) terhadap larva nyamuk Aedes aegypti

\begin{tabular}{clc}
\hline No & \multicolumn{1}{c}{ Ekstrak Sampel } & Nilai LC50 dalam ppm \\
\hline 1 & Ekstrak pekat etanol & 35,64 \\
2 & Ekstrak fraksi n-heksana & 46,24 \\
3 & Ekstrak fraksi etilasetat & 24,56 \\
4 & Ekstrak fraksi n-butanol & 16,78 \\
5 & Ekstrak fraksi air & 34,56
\end{tabular}

Sumber: Ahmad (2012).

Potensi larvasida ekstrak buah Libo, khususnya terhadap larva nyamuk $A$. aegypti sangat kuat yaitu semua ekstrak menunjukkan LC50 dibawah 50 ppm.
Bukti ilmiah ini merupakan potensi yang mudah dimanfaatkan karena berorientasi pada pestisida yaitu insektisida sehingga tidak memerlukan pengujian lebih lanjut 
yang ketat. Uji yang dapat dilakukan ekstrak buah Libo kaitannya dengan potensi pembasmi nyamuk adalah pengujian dilakukan terhadap nyamuk dewasa atau pupil.

\section{E. Kandungan Metabolit Sekunder Buah Libo}

Skrining kandungan metabolit sekunder buah Libo bertujuan untuk mengetahui lebih jauh tentang kemungkinan golongan metabolit sekunder yang memberikan efek sitotoksik, antioksidan, antibakteri, dan efek larvasida pada setiap ekstrak. Golongan metabolit sekunder yang terkandung dalam bual Libo adalah alkaloid (sangat dominan) dan saponin.

\section{KESIMPULAN}

Buah Libo sangat berpotensi dalam bidang kefarmasian yaitu sebagai sumber bahan antioksidan, sitotoksik (antikanker), antibakteri, dan larvasida khususnya sebagai pembasmi larva nyamuk $A$. aegypti. Buah Libo juga mengandung golongan metabolit sekunder yang sangat bervariasi yang memungkinkan masih terdapat potensi lain. Tumbuhan Libo yang berbuah secara menerus merupakan pendukung potensi-potensi tersebut.

\section{UCAPAN TERIMA KASIH}

Terimakasih disampaikan kepada Kepala Laboratorium Penelitian dan Pengembangan Kefarmasian FARMAKA TROPIS Fakultas Farmasi Universitas
Mulawarman yang telah memberikan pelayanan untuk kegiatan penelitian yang terkait dengan Kefarmasian terutama yang berhubungan dengan pemanfaatan sumberdaya alami dalam bidang kefarmasian. Terimakasih juga disampaikan kepada para pembahas skripsi mahasiswa yang telah meningkatkan keilmian setiap tugas akhir mahasiswa sehingga menjadi layak untuk dipublikasikan kepada masyarakat, terutama pada peneliti.

\section{DAFTAR PUSTAKA}

1. Ahmad, P. F., 2012, Uji aktivitas larvasida ekstrak buah Libo ( $F$. varieagata) terhadap larva nyamuk Aedes aegypti, Skripsi, Fakultas Farmasi, Universitas Mulawarman, Samarinda.

2. Ramadhani, A., 2012, Uji antibakteri ekstrak buah Libo ( $F$. varieagata), Skripsi, Fakultas Farmasi Universitas Mulawarman, Samarinda.

3. Rapael, 1991, Natural Products: a Laboratory Guide, Academic Press, London.

4. Titin, R., 2013, Uji antioksidan ekstrak buah Libo ( $F$. varieagata), Skripsi, Fakultas Farmasi, Universitas Mulawarman, Samarinda.

5. Wijaya, V., 2012, Identifikasi kandungan metabolit sekunder dan bioaktivitas ekstrak buah Libo ( $F$. varieagata) terhadap larva Artemia salina, Skripsi, Fakultas Farmasi Universitas Mulawarman, Samarinda. 